\title{
Perspektive der Arbeitgeberverbände
}

\author{
Roland Wolf
}

$\begin{array}{ll}\text { I. EuGH und Arbeitsmarkt } & 109\end{array}$

$\begin{array}{ll}\text { II. EuGH und Tarifrecht } & 109\end{array}$

$\begin{array}{ll}\text { III. Entsendung in der EuGH-Rechtsprechung } & 110\end{array}$

$\begin{array}{ll}\text { IV. Arbeitskampf mit grenzüberschreitendem Charakter } & 110\end{array}$

V. Zusammenfassung 111

\section{EuGH und Arbeitsmarkt}

In vielen Bereichen hat der EuGH mit seinen Entscheidungen tief in die Gestaltungskompetenz des nationalen Gesetzgebers eingegriffen und damit Richtlinienumsetzungen ad absurdum geführt. Aus jüngster Zeit sei an dieser Stelle nur erinnert an die missglückten Entscheidungen in der Rechtssache Mangold, der Rechtssache Pfeiffer und der Rechtssache Jaeger.

Der EuGH hat gerade mit seiner Entscheidung in der Rechtssache Mangold Beschäftigungschancen vertan. Allenfalls insoweit ließe sich die Behauptung rechtfertigen, „das soziale Europa finde nicht statt". Eine solche Aussage ist aber geradezu absurd unter dem Gesichtspunkt, der EuGH schränke Arbeitnehmerrechte ein.

\section{EuGH und Tarifrecht}

Wenn man die Diskussion auf die jüngsten vier Entscheidungen zum Tarifrecht im weiteren Sinne fokussiert (wobei Vergaberecht nicht mit Tarifrecht gleichzusetzen ist), ist festzustellen, dass der EuGH maßvoll widerstreitende Interessen zum Ausgleich gebracht hat. Anders, als es auf den ersten Blick scheinen mag, muss man dabei die Entscheidungen Luxemburg, Rüffert und Laval auf der einen und Viking auf der anderen Seite betrachten. 


\section{Entsendung in der EuGH-Rechtsprechung}

Bei den Entscheidungen Luxemburg, Rüffert und Laval geht es darum, wie ein Mitgliedsstaat der Europäischen Union in die Dienstleistungsfreiheit von Unternehmen aus anderen Mitgliedsstaaten eingreifen darf. $\mathrm{Zu}$ Recht betont der EuGH, dass dies grundsätzlich nur zulässig ist, soweit Primär- oder Sekundärrecht einen solchen Eingriff zulassen. Beim Einsatz entsandter Arbeitnehmer ist ein solcher Eingriff durch das Sekundärrecht vorgesehen, nämlich durch die Entsenderichtlinie.

Der Europäische Gerichtshof arbeitet in den drei vorbezeichneten Entscheidungen den Eingriff in die Dienstleistungsfreiheit am Kanon der Entsenderichtlinie ab. Dies ist - ob man die Entsenderichtlinie für richtig befindet oder nicht - nachvollziehbar. Mitgliedsstaaten dürfen danach nicht aus protektionistischen Erwägungen unter dem Deckmantel des Arbeitnehmerschutzes eigenständige Regelungen erfinden, die den Einsatz von entsendeten Arbeitnehmern entweder unzulässig oder aber doch wirtschaftlich sinnlos machen.

\section{Arbeitskampf mit grenzüberschreitendem Charakter}

In der Rechtssache Viking handelt es sich demgegenüber um eine Entscheidung zum Arbeitskampfrecht. Schon aus diesem Grunde muss gefragt werden, ob die Entscheidung überhaupt vor dem Hintergrund von Artikel 137 Abs. 5 EG-Vertrag hätte ergehen dürfen. Wenn aber der EuGH die Niederlassungsfreiheit durch einen Arbeitskampf berührt sieht, der nach nationalen Vorschriften zulässig ist, muss er dieses nationale Recht in Einklang bringen mit der Grundfreiheit (hier der Niederlassungsfreiheit) des Europarechts.

Der EuGH postuliert sehr klar, dass der bei Viking relevante Boykott als Arbeitskampfmaßnahme der finnischen Gewerkschaft - verstärkt durch die internationale Seearbeitergewerkschaft - nur das mildeste Mittel sein darf, um in Grundfreiheiten einzugreifen. Dabei ist der Arbeitskampf nicht gerechtfertigt als eigenständiges Recht der Gewerkschaft, sondern er wird gerechtfertigt im Verhältnis von Niederlassungsfreiheit zum Schutz der Arbeitnehmerrechte. Anders gewendet: Wo es einen ausreichenden Schutz der Arbeitnehmerrechte auf andere Weise gibt, darf kein Arbeitskampf stattfinden.

Der nationale Gesetzgeber ist daher aufgefordert klarzustellen, dass Arbeitskämpfe um Regelungsmaterien unzulässig sind, die dem Betriebsrat abschließend vorbehalten sind - so in den $\S \S 111 \mathrm{ff}$. BetrVG. 


\section{Zusammenfassung}

Aus den Entscheidungen Luxemburg, Rüffert und Laval ergibt sich für den deutschen Gesetzgeber keinerlei Handlungsbedarf. Die Entscheidungen machen noch einmal deutlich, wie behutsam mit dem Instrument des Mindestlohns umgegangen werden muss. Aus der Entscheidung Viking ergibt sich Handlungsbedarf, wenn das Bundesarbeitsgericht weiter die Grundfreiheiten des europäischen Einigungswerks zu wenig berücksichtigen und Tarifsozialpläne und Streiks um diese weiter für zulässig erachten sollte. 
